02

\title{
Спектрально-люминесцентные свойства циклометаллированных комплексов Pd(II) на основе метилового эфира цинхофена
}

\author{
(C) Р.И. Байчурин ${ }^{1}$, И.Т. Дуланова ${ }^{1}$, Ал.М. Пузык ${ }^{2}$, М.В. Пузык ${ }^{19}$ \\ ${ }^{1}$ Российский государственный педагогический университет имени А.И. Герцена, \\ 191186 Санкт-Петербург, Россия \\ ${ }^{2}$ Санкт-Петебургский государственный университет, \\ 199034 Санкт-Петербург, Россия \\ ฯ e-mail: puzyk@mail.ru
}

Поступила в редакцию 30.04.2021 г.

В окончательной редакции 22.07.2021 г.

Принята к публикации 27.07.2021 г.

Разработана методика синтеза комплексов $\mathrm{Pd}(\mathrm{II})$ с метиловым эфиром 2-фенилхинолин-4-карбоновой кислоты: $[\mathrm{PdMpqc}(\mu-\mathrm{Ac})]_{2}$ и $[\mathrm{PdEnMpqc}] \mathrm{BF}_{4}$, где $\mathrm{Mpqc}$ - метил-2-фенил-4-хинолинкарбоксилат-ион, $\mathrm{Ac}-$ ацетат-ион, En - этилендиамин. Состав и строение полученных комплексов установлены на основании данных ИК и полиядерной спектроскопии ЯМР, оптические и физические свойства описаны на основании УФ и флуоресцентной спектроскопии. Фосфоресценция комплексов $\mathrm{Pd}(\mathrm{II})$ в видимой области отнесена к излучательному переходу из спин-запрещенного внутрилигандного электронно-возбужденного ${ }^{3}(\pi-\pi)$ состояния, локализованного на ароматической системе Мрqс.

Ключевые слова: комплексы $\operatorname{Pd}(\mathrm{II})$, метил-2-фенил-4-хинолинкарбоксилат, спектроскопия ЯМР, спектрально-люминесцентные свойства.

DOI: $10.21883 /$ OS.2021.11.51637.2253-21

Цинхофен (2-фенилцинхониновая кислота) и его производные известны с конца 19 века. Введение различных заместителей в молекулу цинхофена способствует снижению токсичности, повышению растворимости, всасываемости, транспортировки по кровяному руслу и, как следствие, к расширению спектра фармакологического действия (болеутоляющие, жаропонижающие, противоподагрические, антимикробные и противоопухолевые средства) [1-4].

Наличие в молекуле цинхофена атомов кислорода и азота способствует его комплексообразованию с некоторыми d-металлами. Так, катионы $\mathrm{Zn}(\mathrm{II})$ и $\mathrm{Cd}(\mathrm{II})$ coединяются через атомы кислорода карбоксильной группы $[5,6]$, а $\mathrm{Au}(\mathrm{III})$ и металлы платиновой группы $\mathrm{Pt}(\mathrm{II})$, $\operatorname{Pd}(\mathrm{II}), \operatorname{Rh}(\mathrm{III}), \operatorname{Ir}(\mathrm{III})$ координируются через азот и депротонированный углерод фенильного кольца [7-12]. Однако фотофизические характеристики подробно исследованы только для октаэдрических $\mathrm{Ir}(\mathrm{III}), \mathrm{Rh}(\mathrm{III})$ и плоскоквадратного $\mathrm{Pt}(\mathrm{II})$ комплексов [8,10-12]. Металлированные цинхофены - это часть большого сообщества циклометаллированных комплексов, интенсивная люминесценция которых в сочетании с особенностью электронного строения привлекает внимание исследователей при разработке светоиндуцирующих устройств (типа OLED) [13], сенсоров на молекулярный кислород [14], ионы тяжелых элементов [15], pH, люминесцентные маркеры биомолекул [11], а также применяются для фотодинамической терапии [16].

Однако для электронного аналога $\mathrm{Pt}(\mathrm{II})$ - комплексов $\mathrm{Pd}(\mathrm{II})$ с цинхофеном люминесцентные исследования отсутствуют [9]. В настоящей работе представлены результаты спектрально-люминесцентных исследований соединений $[\operatorname{PdMpqc}(\mu-\mathrm{Ac})]_{2}(2)$ и $\left[\mathrm{PdEnMpqc}_{\mathrm{B}} \mathrm{BF}_{4}(\mathbf{3})\right.$, где Мрqс - депротонированная форма метил-2-фенил4-хинолинкарбоксилат-иона, Ас — ацетат-ион, En этилендиамин (рис. 1).

\section{Экспериментальная часть}

Спектральные исследования выполнены с использованием оборудования Центра коллективного пользования факультета химии Российского государственного педагогического университета им. А.И. Герцена. Спектры ЯMP ${ }^{1} \mathrm{H},{ }^{13} \mathrm{C}^{1} \mathrm{H},{ }^{1} \mathrm{H}-{ }^{1} \mathrm{H}$ COSY, ${ }^{1} \mathrm{H}-{ }^{1} \mathrm{H}$ NOESY, ${ }^{1} \mathrm{H}_{-}{ }^{13} \mathrm{C}$ HMQC, ${ }^{1} \mathrm{H}^{-13} \mathrm{C}$ НMBC и ${ }^{1} \mathrm{H}_{-}{ }^{15} \mathrm{~N}$ НМВС регистрировали на спектрометре Jeol ECX400A с рабочими частотами $399.78\left({ }^{1} \mathrm{H}\right), 100.53\left({ }^{13} \mathrm{C}\right)$ и $40.52 \mathrm{MHz}\left({ }^{15} \mathrm{~N}\right)$; растворитель - ДМСО- $d_{6}$. В качестве внутреннего стандарта использовали сигналы остаточных протонов недейтерированного растворителя. Химические сдвиги ${ }^{15} \mathrm{~N}$ определялись относительно $\mathrm{CH}_{3} \mathrm{NO}_{2}$. ИК спектры получены на фурье-спектрометре Shimadzu IRPrestige-21 в таблетках KBr. Электронные абсорбционные спектры получали при комнатной температуре в 96\%-ном этаноле на СФ-2000 („ОКБ Спектр“, СанктПетербург, Россия). Люминесцентные исследование проводили при $77 \mathrm{~K}$ на спектрофлуориметре Флюорат-02Панорама (ГК „Люмэкс“, Санкт-Петербург, Россия).

Метил-2-фенилхинолин-4-карбоксилат (НМрqс), тетрафтороборат аммония $\left(\mathrm{NH}_{4} \mathrm{BF}_{4}\right)$ (коммерческие вещества, Sigma-Aldrich, „Нева реактив“) были использованы 

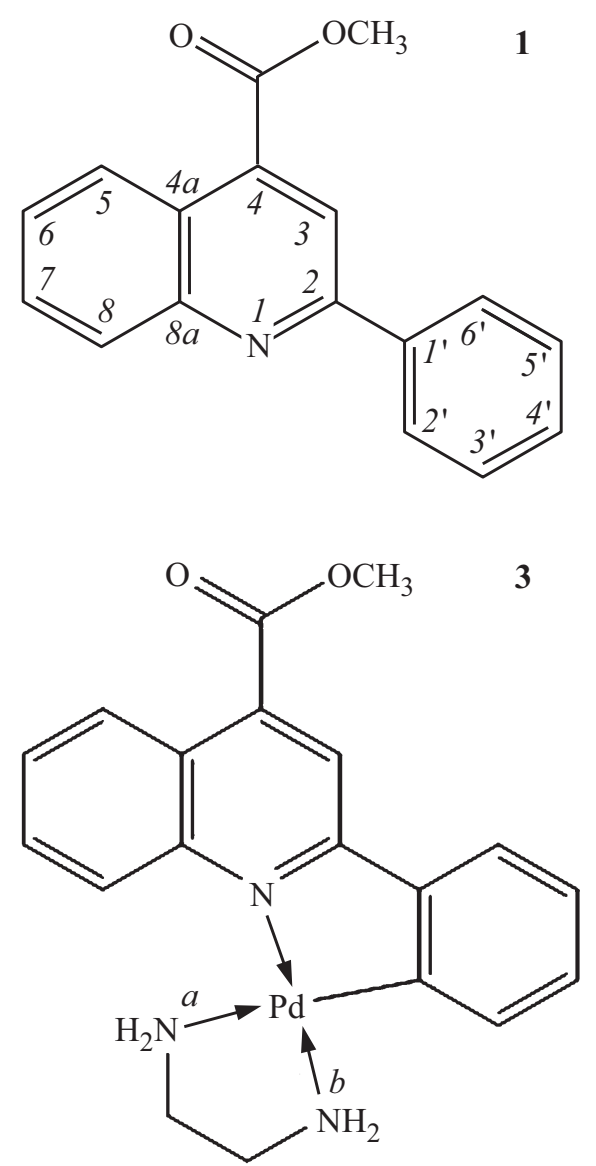<smiles></smiles>

Рис. 1. Структурные формулы метил-2-фенилхинолин-4-карбоксилата (1) и циклопалладированных комплексов: $[\operatorname{PdMpqc}(\mu-\mathrm{Ac})]_{2}(\mathbf{2})$ и $[\mathrm{PdEnMpqc}] \mathrm{BF}_{4}(\mathbf{3})$.

без дополнительной очистки. Все растворители очищали с использованием стандартных методик [17].

Комплекс 2 получали при нагревании $89 \mathrm{mg}$ $(0.4 \mathrm{mmol})$ ацетата палладия $\operatorname{Pd}(\mathrm{Ac})_{2} \quad$ и $105 \mathrm{mg}$ $(0.4 \mathrm{mmol}) \quad 1$ в ледяной уксусной кислоте $(5.0 \mathrm{ml})$. $\mathrm{O}$ протекании химической реакции судили по смене цвета раствора с коричневого на красный и выпадению осадка при упаривании реакционной смеси вдвое. Собранный на фильтре и промытый холодным дихлорметаном осадок сушили на воздухе до постоянного веса. Масса продукта составила $150 \mathrm{mg}$, выход - $90 \%$.

Синтез комплекса 3 состоял из двух стадий. Вначале к взвеси, состоящей из $20 \mathrm{mg}(0.023 \mathrm{mmol}) 2$ и $8 \mathrm{ml}$ теплого метанола $\left(50^{\circ} \mathrm{C}\right)$, добавили $0.2 \mathrm{ml} 0.24 \mathrm{~mol} / 1$ водного раствора этилендиамина. Наблюдали растворение 2 и изменение цвета раствора с красного на желтый. Далее к полученному теплому раствору приливали насыщенный раствор тетрафторобората аммония до начала выпадения осадка. После охлаждения суспензии до комнатной температуры осадок собирали на фильтре и промывали холодным метанолом, сушили на воздухе до постоянного веса. Масса продукта составила $20 \mathrm{mg}$, выход - 81\%.

Метил-2-фенилхинолин-4-карбоксилат (НМрqс, 1). Спектр ЯМР ${ }^{1} \mathrm{H}, \delta$, ppm: 3.97 с $\left(3 \mathrm{H}, \mathrm{CH}_{3}\right), 7.45-7.55 \mathrm{M}$ $\left(3 \mathrm{H}, \mathrm{H}^{3^{\prime}, 4^{\prime}, 5^{\prime}}\right), 7.64$ д. д. д. $\left(1 \mathrm{H}, \mathrm{H}^{6},{ }^{3} J_{5,6} 8.50,{ }^{3} J_{6,7} 6.95\right.$, $\left.{ }^{4} J_{6,8} 1.35 \mathrm{~Hz}\right), 7.79$ д. д. Д. $\left(1 \mathrm{H}, \mathrm{H}^{7},{ }^{3} J_{7,8} 8.45,{ }^{3} J_{6,7} 6.95\right.$, $\left.{ }^{4} J_{5,7} 1.25 \mathrm{~Hz}\right), 8.10$ д. Д.д. $\left(1 \mathrm{H}, \mathrm{H}^{8},{ }^{3} J_{7,8} 8.45,{ }^{4} J_{6,8} 1.35\right.$, $\left.{ }^{5} J_{5,8} \quad 0.50 \mathrm{~Hz}\right), \quad 8.19-8.24 \quad\left(2 \mathrm{H}, \quad \mathrm{H}^{2^{\prime}, 6^{\prime}}\right), 8.39 \mathrm{c}\left(\mathrm{H}^{3}\right)$, 8.51 д. д. д. $\left(1 \mathrm{H}, \mathrm{H}^{5},{ }^{3} J_{5,6} 8.50,{ }^{4} J_{5,7} 1.25,{ }^{5} J_{5,8} 0.50 \mathrm{~Hz}\right)$. Спектр ЯМР ${ }^{13} \mathrm{C}\left\{{ }^{1} \mathrm{H}\right\}, \delta$, ppm: $53.43\left(\mathrm{CH}^{3}\right), 119.88\left(\mathrm{C}^{3}\right)$, $123.67\left(\mathrm{C}^{4}\right), 125.61\left(\mathrm{C}^{5}\right), 127.71\left(\mathrm{C}^{2^{\prime}, 6^{\prime}}\right), 128.48\left(\mathrm{C}^{6}\right)$, $129.48\left(C^{3^{\prime}, 5^{\prime}}\right), 130.35\left(C^{8}\right), 130.55\left(C^{4^{\prime}}\right), 130.83\left(C^{7}\right)$, $136.60\left(\mathrm{C}^{4 \mathrm{a}}\right), 138.24\left(\mathrm{C}^{1^{\prime}}\right), 148.85\left(\mathrm{C}^{8 \mathrm{a}}\right), 156.20\left(\mathrm{C}^{2}\right)$, $166.75(\mathrm{C}=\mathrm{O})$. Спектр ЯМР ${ }^{15} \mathrm{~N}, \delta$, ppm: -62.65 .

Бис-(( $\mu$-ацетато)-метил-2-фенил-4-хинолинкарбоксилатопалладий(II)) (2). Плохорастворимый красный порошок. Спектр ЯМР ${ }^{1} \mathrm{H}, \delta$, ppm: $2.11 \mathrm{c}(3 \mathrm{H}$, ацетат), $4.11 \mathrm{c}\left(3 \mathrm{H}, \mathrm{CH}_{3}\right), 6.11 \mathrm{~T}(1 \mathrm{H}, J 6.41 \mathrm{~Hz}), 6.24$ д $(1 \mathrm{H}$, $J 6.71 \mathrm{~Hz}), 6.50$ т $(1 \mathrm{H}, J 6.30 \mathrm{~Hz}), 7.03$ д $(1 \mathrm{H}, J 7.32 \mathrm{~Hz})$, 7.53 т $(1 \mathrm{H}, J 7.20 \mathrm{~Hz}), 7.64$ т $(1 \mathrm{H}, J 7.10 \mathrm{~Hz}), 8.17$ д $(1 \mathrm{H}$, $J 8.24 \mathrm{~Hz}), 8.37$ д (1H, J $7.93 \mathrm{~Hz})($ всего $8 \mathrm{H}$, бензольное и хинолиновые кольца). Спектр ЯМР ${ }^{13} \mathrm{C}\left\{{ }^{1} \mathrm{H}\right\}$ не удалось измерить по причине низкой растворимости соединения. Спектр ИК (KBr), v, $\mathrm{cm}^{-1}$ : 1725 (O-C=O), 1367, 1267, $1247(\mathrm{C}=\mathrm{N} / \mathrm{C}=\mathrm{C}) . \mathrm{C}_{38} \mathrm{H}_{30} \mathrm{~N}_{2} \mathrm{O}_{8} \mathrm{Pd}_{2}$, найдено (\%) C 53.47; Н 3.53; N 3.28, вычислено (\%) С 53.40; Н 3.51; N 3.28.

Тетрафтороборат метил-2-фенил-4-хинолинкарбоксилатоэтилендиаминпалладия(II) (3). Спектр ЯМР ${ }^{1} \mathrm{H}$, $\delta$, ppm: $2.58-2.64$ м $\left(2 \mathrm{H}, \mathrm{CH}_{2}\right), 2.68-2.75 \mathrm{M}(2 \mathrm{H}$, 
$\left.\mathrm{CH}_{2}\right), 4.03$ с $\left(3 \mathrm{H}, \mathrm{CH}_{3}\right), 4.43$ уш. с $\left(\mathrm{NH}_{2}^{a}\right), 5.40$ уш. с $\left(\mathrm{NH}_{2}^{b}\right), 7.13-7.16 \mathrm{м}\left(1 \mathrm{H}, \mathrm{H}^{3^{\prime}}\right), 7.16-7.25 \mathrm{м}\left(2 \mathrm{H}, \mathrm{H}^{4^{\prime}, 5^{\prime}}\right)$, $7.94-7.98$ м $\left(1 \mathrm{H}, \mathrm{H}^{6^{\prime}}\right), 7.76$ д.д.д. $\left(1 \mathrm{H}, \mathrm{H}^{6},{ }^{3} J_{5,6} 8.30\right.$, $\left.P^{3} J_{6,7} 7.10,{ }^{4} J_{6,8} 1.00 \mathrm{~Hz}\right), 7.85$ д. д. д. $\left(1 \mathrm{H}, \mathrm{H}^{7},{ }^{3} J_{7,8} 8.54\right.$, $\left.{ }^{3} J_{6,7} 7.10,{ }^{4} J_{5,7} 1.30 \mathrm{~Hz}\right), 7.98$ д $\left(1 \mathrm{H}, \mathrm{H}^{8},{ }^{3} J_{7,8} 8.54\right)$, 8.44 д.д. $\left(1 \mathrm{H}, \mathrm{H}^{5},{ }^{3} J_{5,6} 8.30,{ }^{4} J_{5,7} 1.30\right), 8.54 \mathrm{c}\left(\mathrm{H}^{3}\right)$. Спектр ЯМР ${ }^{13} \mathrm{C}\left\{{ }^{1} \mathrm{H}\right\}, \delta$, ppm: $44.47\left(\mathrm{CH}_{2}\right), 46.37\left(\mathrm{CH}_{2}\right)$, $53.95\left(\mathrm{CH}_{3}\right), 118.47\left(\mathrm{C}_{3}\right), 124.21\left(\mathrm{C}_{4}\right), 125.80\left(\mathrm{C}^{5^{\prime}}\right)$, $126.36\left(C^{5}\right), 126.65\left(C^{8}\right), 127.17\left(C^{6}\right), 128.95\left(C^{6}\right)$, $130.52\left(\mathrm{C}^{4^{\prime}}\right), 132.54\left(\mathrm{C}^{7}\right), 134.08\left(\mathrm{C}^{3^{\prime}}\right), 139.95\left(\mathrm{C}^{4 \mathrm{a}}\right)$, $146.55\left(\mathrm{C}^{1^{\prime}}\right), 148.02\left(\mathrm{C}^{8 \mathrm{a}}\right), 156.39\left(\mathrm{C}^{2}\right), 16.12(\mathrm{C}=\mathrm{O})$, $166.61\left(\mathrm{C}^{2^{\prime}}\right)$. Спектр ЯМР ${ }^{15} \mathrm{~N}, \delta$, ppm: -142.06 . ИК спектр (KBr), v, cm ${ }^{-1}: 3335,3278,3258(\mathrm{NH}), 1728$ (O$\mathrm{C}=\mathrm{O}), 1367,1276,1236(\mathrm{C}=\mathrm{N} / \mathrm{C}=\mathrm{C}), 1122,1109,1080$, 622 (B-F). $\mathrm{C}_{19} \mathrm{H}_{20} \mathrm{~N}_{3} \mathrm{O}_{2} \mathrm{BF}_{4} \mathrm{Pd}$ : найдено (\%) C 44.30; Н 3.90; N 8.19, вычислено (\%) С 44.27; Н 3.88; N 8.16.

\section{Результаты и обсуждение}

Комплексные соединения $\operatorname{Pd}(\mathrm{II}) 2$ и 3 были синтезированы согласно следующим реакциям:

$$
2 \mathrm{PdAc}_{2}+2 \mathrm{HMpqc}=[\operatorname{PdMpqc}(\mu-\mathrm{Ac})]_{2 \downarrow}+2 \mathrm{CH}_{3} \mathrm{COOH},
$$

$[\operatorname{PdMpqc}(\mu-\mathrm{Ac})]_{2}+2 \mathrm{En}=2[\operatorname{PdEnMpqc}] \mathrm{Ac}$,

$[\mathrm{PdEnMpqc}] \mathrm{Ac}+\left(\mathrm{NH}_{4}\right) \mathrm{BF}_{4}=[\mathrm{PdEnMpqc}] \mathrm{BF}_{4}+\mathrm{NH}_{4} \mathrm{Ac}$.

Состав и строение соединений 2 и 3 были подтверждены данными ИК и ЯМР ${ }^{1} \mathrm{H}$ и ${ }^{13} \mathrm{C}\left\{{ }^{1} \mathrm{H}\right\}$ спектроскопии с привлечение гомо- $\left({ }^{1} \mathrm{H}^{-1} \mathrm{H}\right.$ COSY, ${ }^{1} \mathrm{H}-{ }^{1} \mathrm{H}$ NOESY $)$ и гетероядерных $\left({ }^{1} \mathrm{H}^{-13} \mathrm{C}\right.$ HMQC, ${ }^{1} \mathrm{H}_{-}{ }^{13} \mathrm{C}$ HMBC и ${ }^{1} \mathrm{H}^{-15} \mathrm{~N}$ НMВC) экспериментов, а также в сравнении с данными некоординированного 1 (см. дополнительные материалы).

В ИК спектрах 2, 3 присутствуют характеристические частоты валентных и деформационных $\mathrm{C}=\mathrm{C}$-, $\mathrm{C}=\mathrm{N}$-колебаний $\quad$ в области $1500-1200 \mathrm{~cm}^{-1}, \mathrm{~N}-\mathrm{H}-$ колебаний в области 3350-3200 $\mathrm{m}^{-1}$, колебаний $\mathrm{COO}^{-}$группы - при $1720-1560 \mathrm{~cm}^{-1}$ и $1420-1240 \mathrm{~cm}^{-1}$, a также колебаний B-F тетрафтороборат-иона, находящегося во внешней сфере комплекса, при 1100-1070 и $622 \mathrm{~cm}^{-1}$ [18] (см. дополнительные материалы).

В ЯМР ${ }^{1} \mathrm{H}$ спектре соединения 1 наблюдаются группы сигналов фенильных протонов $\left(\mathrm{H}^{2^{\prime}}-\mathrm{H}^{6^{\prime}}\right)$ в области $7.45-8.24 \mathrm{ppm}$, протонов хинолинового кольца $\left(\mathrm{H}^{1}-\mathrm{H}^{8}\right)$ в области 7.64-8.51 ppm, а также протонов метильной группы $\left(\mathrm{CH}_{3}\right)$ при $3.97 \mathrm{ppm}$, что согласуется с литературными данными [19-25]. Маркерным принят сигнал протона $\mathrm{H}^{3}$ хинолинового цикла в орто-положении к метилкарбоксилатной группе, проявляющийся в виде синглета при $8.39 \mathrm{ppm}$. В спектре ${ }^{1} \mathrm{H}-{ }^{1} \mathrm{H}$ NOESY coединения 1 присутствующие кросс-пики между сигналами протонов $\mathrm{H}^{5} / \mathrm{CH}_{3}$ и $\mathrm{H}^{3} / \mathrm{CH}_{3}$ свидетельствуют о конформационной подвижности сложноэфирного фрагмента. Также обращает на себя внимание кросс-пик (присутствует также в спектре соединения 3) между сигналами протонов $\mathrm{H}^{3} / \mathrm{H}^{6^{\prime}}$, что свидетельствует об их сближении в пространстве - нахождении в одной плоскости.

Использование спектроскопии ${ }^{1} \mathrm{H}^{13} \mathrm{C}$ HMQC позволило надежно идентифицировать протонированные атомы углерода, а непротонированные атомы углерода по анализу кросс-пиков (через 2-3 связи). В спектре ${ }^{1} \mathrm{H}-{ }^{13} \mathrm{C}$ НМВС соединения 3 следует отметить следующие важные для идентификации кросс-пики:

- кросс-пики $\mathrm{H}^{6^{\prime}} / \mathrm{C}^{2}$ позволили определить $\mathrm{C}^{2}$,

- кросс-пики $\mathrm{H}^{3} / \mathrm{C}^{1^{\prime}}, \mathrm{H}^{5^{\prime}} / \mathrm{C}^{1^{\prime}}, \mathrm{H}^{3^{\prime}} / \mathrm{C}^{1^{\prime}}$ позволили определить $\mathrm{C}^{1^{\prime}}$,

- кросс-пики $\mathrm{H}^{3} / \mathrm{C}^{4}$ позволили определить $\mathrm{C}^{4}$,

- кросс-пики $\mathrm{H}^{3} / \mathrm{C}^{4 a}, \mathrm{H}^{5} / \mathrm{C}^{4 a}$ позволили определить $\mathrm{C}^{4 a}$,

- кросс-пики $\mathrm{H}^{5} / \mathrm{C}^{8 a}, \quad \mathrm{H}^{7} / \mathrm{C}^{8 a}$ позволили определить $\mathrm{C}^{8 a}$.

- кросс-пики протонов и атомов углерода метиленовых групп этилендиамина (2.58-2.64/44.47 и 2.682.75/46.37 ppm).

O комплексообразовании между 1 и $\operatorname{Pd}(\mathrm{II})$ судили по координационно-индуцированному сдвигу пиков $\left(\mathrm{CIS}=\delta_{\text {комплекса }}-\delta_{\text {лиганда }}\right)$ сигналов ядер водорода и углерода (табл. 1). Положительная величина CIS указывает на смещение резонансов в слабое поле, т.е. на снижение электронной плотности на атомах лиганда Mpqc. Наибольшее значение CIS зафиксировано для атома углерода $\mathrm{C}^{2}$, который подвергся депротонированию и образовал химическую связь с палладием. Наибольшая отрицательная величина CIS, зафиксированная для $\mathrm{C}^{8}$ хинолинового кольца, указывает на смещение резонансов в сильное поле и, следовательно, на повышение электронной плотности на атомах лиганда. Это, возможно, обусловлено $\pi$-дативным взаимодействием палладия с хинолиновым кольцом.

Также следует отметить присутствие в спектре ${ }^{1} \mathrm{H}-{ }^{1} \mathrm{H}$ NOESY комплекса 3 кросс-пиков между сигналами протонов $\mathrm{H}^{8} / \mathrm{NH}_{2}^{a}$ и $\mathrm{H}^{3^{\prime}} / \mathrm{NH}_{2}^{b}$, что позволяет разнести сигналы протонов неэквивалентных аминогрупп. Наблюдается также корреляция сигналов протонов $\mathrm{NH}_{2}^{a}(4.43 \mathrm{ppm})$ и метиленовых протонов при $2.58-2.64$ ррm и сигналов протонов $\mathrm{NH}_{2}^{b}(5.40 \mathrm{ppm})$ и метиленовых протонов при $2.68-2.75$ ppm. Спин-спиновая связанность протонов была доказана анализом спектров ${ }^{1} \mathrm{H}-{ }^{1} \mathrm{H}$ COSY по наличию соответствующих кросс-пиков. Совокупность полученных данных позволяет утверждать о плоскостном нахождении атомов азота этилендиамина, атомов фенильного и хинолинового колец и центрального иона $-\operatorname{Pd}(\mathrm{II})$.

Использование методики ${ }^{1} \mathrm{H}_{-}{ }^{15} \mathrm{~N}$ НМВС-эксперимента (наличие кросс-пика с протоном $\mathrm{H}^{8}$ ) позволяет приписать атомам азота хинолина химический сдвиг $\left(\delta_{\mathrm{N}}\right)$ при $-62.65 \mathrm{ppm}$ в свободном лиганде (НМрqс) и $-142.06 \mathrm{ppm}$ в соединении 3. Такие значения $\delta_{\mathrm{N}}$ сигнала атома азота хинолинового кольца согласуются с литературными данными. Например, для незамещенного хинолина -77.5 [19], а комплексообразование с катионом серебра приводит к смещению в сильное поле на 23-30 ppm, -75 [20], -71.1 ppm [21], 
Таблица 1. Координационно-индуцированные сдвиги (CIS, ppm) углерода и водорода в комплексе 3; нумерация атомов приведена на рис. 1

\begin{tabular}{|c|c|c|c|c|c|c|c|c|c|c|c|}
\hline Углерод & $\mathrm{CH}_{3}$ & $\mathrm{C}^{16}$ & $\mathrm{C}^{2 / 2^{6}}$ & \multicolumn{2}{|c|}{$C^{3 / 3^{6}}$} & $C^{4 / 4 a}$ & $\mathrm{C}^{5}$ & $\mathrm{C}^{6}$ & $\mathrm{C}^{7}$ & $C^{8 / 8 a}$ & $\mathrm{C}=\mathrm{O}$ \\
\hline \multirow[t]{3}{*}{ CIS } & 0.52 & 8.31 & $4.19 / 38.9$ & \multicolumn{2}{|c|}{$-0.96 / 3.6$} & $0.54 / 3.35$ & 0.75 & 0.47 & 1.67 & $-3.7 /-0.63$ & -0.63 \\
\hline & & & Водород & $\mathrm{CH}_{3}$ & $\mathrm{H}^{3}$ & $\mathrm{H}^{5}$ & $\mathrm{H}^{6}$ & $\mathrm{H}^{7}$ & $\mathrm{H}^{8}$ & & \\
\hline & & & CIS & 0.06 & 0.15 & 0.07 & 0.12 & 0.06 & -0.12 & & \\
\hline
\end{tabular}

для 2-(4-метоксифенил)хинолин-4-карбоновой кислоты

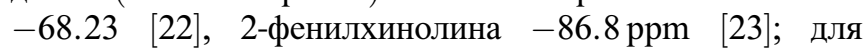
палладиевого диацетатного димера, полученного из 4-(2-бромфенокси)-6-фенилхинолина, -191.3 ppm [24], для дигидробис(трифенилфосфин)родий(III) комплекca, полученного из хинолин-2-карбоновой кислоты, -114.1 [25]. Приведены литературные данные относительно нитрометана (если в статье использовался иной стандарт, то нами производился пересчет данных, принимая химический сдвиг нитрометана равным 388 ppm относительно $\mathrm{NH}_{3}$ ).

Электронные абсорбционные и эмиссионные свойства соединений 1-3 могут быть рассмотрены в рамках теории локализованных молекулярных орбиталей [26], т.е. молекулярные орбитали преимущественно локализованы либо на $\mathrm{Pd}(\mathrm{II})$, либо на лиганде Mpqc (табл. 2). Спектры поглощения в растворе этанола соединений 1-3 (рис. 2) характеризуются рядом спин-разрешённых переходов различной интенсивности и орбитальной природы:

- в коротковолновой области (до $360 \mathrm{~nm}$ ) более интенсивные $\left(\varepsilon>10^{4} \mathrm{l} / \mathrm{mol} \cdot \mathrm{cm}\right)$ внутрилигандные переходы (ВЛ) локализованы на ароматической системе фрагмента Мрqс и представляют собой переходы ${ }^{1}\left(\pi-\pi^{*}\right)$ типа; в спектрах комплексов 2 и 3 благодаря комплексообразованию - депротонированию 1 и образованию связи С-Pd ВЛ переходы батохромно смещены;

- в более длиноволновой области (более $390 \mathrm{~nm}$ ) проявляются менее интенсивные полосы $\left(\varepsilon>10^{3} \mathrm{l} / \mathrm{mol} \cdot \mathrm{cm}\right)$ переноса заряда с металла на лиганд (ПЗМЛ) или переходы ${ }^{1}\left(d-\pi^{*}\right)$-типа, которые отсутствуют в спектре поглощения 1.

Спектр люминесценции 1 при комнатной температуpe симметричен длинноволновой полосе поглощения. Незначительный стоксовый сдвиг $\left(\sim 4700 \mathrm{~cm}^{-1}\right)$ и наносекундный диапазон времени жизни люминесценции позволяют утверждать, что флуоресценция $\mathbf{1}$ происходит из низшего спин-разрешенного ВЛ состояния и представляет собой переход ${ }^{1}\left(\pi-\pi^{*}\right)$-типа.

Для всех циклометаллированных комплексов $\mathrm{Pd}(\mathrm{II})$ характерно эффективное температурное тушение люминесценции [27-29]. Комплексы 2 и 3 люминесцируют только при $77 \mathrm{~K}$ и в более длинноволновой области, чем 1. Согласие спектров возбуждения фосфоресценции со спектрами поглощения комплексов и экспоненциальный характер затухания фосфоресценции свидетельствуют о протекании излучательного процесса деградации энергии фотовозбуждения из низшего
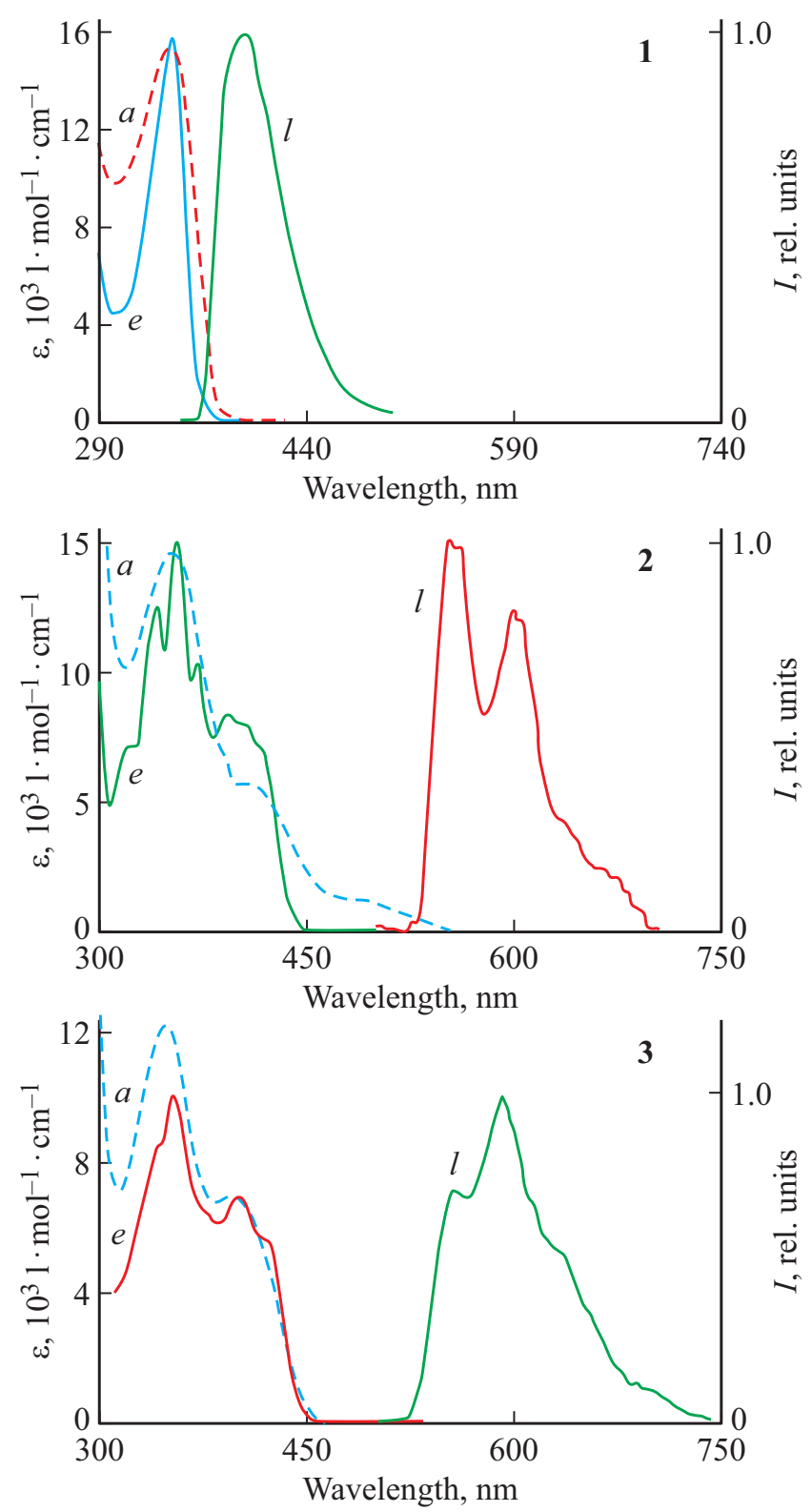

Рис. 2. Спектры поглощения (a) (при 290 К), нормированные спектры возбуждения люминесценции $(e)$ и люминесценции $(l)$ соединений 1-3 в этаноле при $77 \mathrm{~K}$.

по энергии электронно-возбужденного состояния комплекса 3. Колебательная структура низкотемпературных 
Таблица 2. Спектрально-люминесцентные характеристики комплексов и лигандов

\begin{tabular}{|c|c|c|c|c|}
\hline \multirow[b]{2}{*}{ Соединение } & \multicolumn{2}{|c|}{ Поглощение } & \multicolumn{2}{|c|}{ Люминесценция } \\
\hline & $\begin{array}{c}\lambda_{\max }, \mathrm{nm} \\
\left(\varepsilon \cdot 10^{3}, 1 / \mathrm{mol} \mathrm{cm}\right)\end{array}$ & Отнесение & $\lambda_{\max }, \mathrm{nm}$ & $\tau, \mu \mathrm{s}$ \\
\hline 1 & $337(15.4)$ & ${ }^{1}\left(\pi-\pi^{*}\right)$ & 400 & - \\
\hline \multirow[t]{3}{*}{2} & $350(14.6)$ & ${ }^{1}\left(\pi-\pi^{*}\right)$ & 556 & $100^{* * * *}$ \\
\hline & $402(7.3)$ & ${ }^{1}\left(d-\pi^{*}\right)$ & $598^{* * *}$ & \\
\hline & $490(1.4)$ & ${ }^{1}\left(d-\pi^{*}\right)$ & & \\
\hline \multirow[t]{2}{*}{3} & $352(12.2)$ & ${ }^{1}\left(\pi-\pi^{*}\right)$ & 556 & 135 \\
\hline & $400(7.0)$ & ${ }^{1}\left(d-\pi^{*}\right)$ & $600^{* * *}$ & \\
\hline \multirow{3}{*}{$\begin{array}{c}{\left[\operatorname{IrDppb}^{*}(\mathrm{Mpqc})_{2}\right]^{+}} \\
{[11]}\end{array}$} & $255^{\Pi}(86)$ & ${ }^{1}\left(\pi-\pi^{*}\right)$ & 620 & $0.43^{* * * *}$ \\
\hline & $284(31)$ & ${ }^{1}\left(\pi-\pi^{*}\right)$ & & \\
\hline & $361(14)$ & ${ }^{1}\left(\pi-\pi^{*}\right)$ & & \\
\hline \multirow{3}{*}{$\begin{array}{c}{\left[\mathrm{PtDppb}^{*} \mathrm{Mpqc}\right]^{+}} \\
{[11]}\end{array}$} & $275^{\Pi}(31)$ & ${ }^{1}\left(\pi-\pi^{*}\right)$ & $620^{\Pi}$ & 0.38 \\
\hline & $358(8.3)$ & ${ }^{1}\left(\pi-\pi^{*}\right)$ & 648 & \\
\hline & $410^{\Pi}(2.6)$ & ${ }^{1}\left(d-\pi^{*}\right)$ & & \\
\hline \multirow{3}{*}{$\begin{array}{c}{\left[\mathrm{RhDppz}^{* *}(\mathrm{Mpqc})_{2}\right]^{+}} \\
{[10]}\end{array}$} & $278(32.5)$ & ${ }^{1}\left(\pi-\pi^{*}\right)$ & 576 & 0.128 \\
\hline & $361(12.0)$ & ${ }^{1}\left(\pi-\pi^{*}\right)$ & & \\
\hline & $426(1.8)$ & ${ }^{1}\left(d-\pi^{*}\right)$ & & \\
\hline
\end{tabular}

Примечание. ${ }^{*} \mathrm{Dppb}$ - бис(дифенилфосфино)бензол, ${ }^{* *} \mathrm{Dppz}$ - дипиридо[3,2-a:2',3'-c]феназин, ${ }^{* * *}$ - величина колебательного расщепления $\sim 1300 \mathrm{~cm}^{-1},{ }^{* * * *}$ - немоноэкспоненциально, п

спектров фосфоресценции комплексов $\mathrm{Pd}(\mathrm{II})$ с частотой $1300 \mathrm{~cm}^{-1}$, близкой к частоте валентных колебаний связей $\mathrm{C}=\mathrm{C} / \mathrm{C}=\mathrm{N}$ Mpqc, и относительно длительное время затухания $(135 \mu \mathrm{s})$ позволяют отнести фосфоресценцию комплексов к спин-запрещенному внутрилигандному оптическому переходу ${ }^{3}\left(\pi-\pi^{*}\right)$-типа, преимущественно локализованному на ароматической системе Мрqс-лиганда.

Максимум люминесценции комплексов $\operatorname{Pd}(\mathrm{II}) \mathbf{2}$ и 3 имеет гипсохромный сдвиг по сравнению с комплексами $\mathrm{Rh}(\mathrm{III}), \operatorname{Pt}(\mathrm{II})$ и $\operatorname{Ir}(\mathrm{III})$, которые также содержат лиганд Мpqc $[8,10,11]$. Вероятно, это обусловлено влиянием ряда факторов: природой и степенью окисления металла, различием донорно-акцепторных свойств нецинхофенового лиганда (этилендиамин, бис(дифенилфосфино)бензол, дипиридо [3,2-a:2',3'с]феназин) [29].

Таким образом, комплексообразование, влияние тяжелого атома $\mathrm{Pd}(\mathrm{II})$ привело к появлению долгоживущей фосфоресценции, обусловленной ароматической системой Мрqс-лиганда.

\section{Финансирование работы}

Работа выполнена в рамках государственного задания при финансовой поддержке Минпросвещения России (проект № FSZN-2020-0026).

\section{Конфликт интересов}

Авторы заявляют, что у них нет конфликта интересов.

\section{Список литературы}

[1] Palmer W.L., Woodall P.S. // JAMA. 1936. V. 107. N 10. P. 760. doi 10.1001/jama.1936.02770360006003

[2] Мелентьева Г.А., Антонова Л.А. Фармацевтическая химия. М.: Медицина, 1985. 317 с.

[3] Dexter D.L., Hesson D.P., Ardecky R.J., Rao G.V., Tippett D.L., Dusak B.A., Paull K.D., Plowman J., DeLarco B.M., Narayanan V.L., Forbes M. // Cancer Research. 1985. V. 45. N 11. Part. 1. P. 5563.

[4] Wang X., Xie X., Cai Y., Yang X., Li J., Li Y., Chen W., He M. // Molecules. 2016. V. 21. N 3. Article № 340 (15 p.). doi 10.3390/molecules 21030340

[5] Bing Y., Li X., Zha M.-Q., Wang D.-J. // Synthesis and Reactivity in Inorganic, Metal-Organic, and Nano-Metal Chemistry. 2011. V. 41. P. 798. doi 10.1080/15533174.2011.591306

[6] Lei N., Ren Q.-L., Liu Y.-P., Li J., Cong P., Qin J., Zhu H.-L. // J. Molecular Structure. 2014. V. 1067. N 5. P. 220. doi org/10.1016/j.molstruc.2014.03.052 0022-2860

[7] Parish R.F., Wright J.P., Pritchard R.J. // J. of Organomet. Chem. 2000. V. 596. P. 165. doi 10.1016/S0022328X(99)00645-2

[8] Stacey O.J., Platts J.A., Coles S.J., Horton P.N., Pope S.J.A. // Inorg. Chem. 2015. V. 54(13). P. 6528. doi 10.1021/acs.inorgchem.5b00817

[9] Sternberg M., Rust J., Lehmann C.W., Mohr F. // Helvetica Chimica Acta. 2013. V. 96. P. 280. doi 10.1002/hlca.201200386

[10] Hao T., Yin C., Yang X., Fu Y., Zheng X., Li R., Xiao D., Chen H. // Eur. J. Inorg. Chem. 2017. V. 36. N 10. P. 4149. doi 10.1002/ejic. 201700700

[11] Solomatina A.I., Su S.-H., Lukina M.M., Dudenkova V.V., Shcheslavskiy V.I., Wu C.-H., Chelushkin P.S., Chou P.-T., Koshevoy I.O., Tunik S.P. // RSC Adv. 2018. V. 8. P. 17224. doi $10.1039 / \mathrm{c} 8 \mathrm{ra} 02742 \mathrm{k}$ 
[12] Smith R.A., Stokes E.C., Langdon-Jones E.E., Platts J.A., Kariuki B.M., Hallett A.J., Pope S.J.A. // Dalton Trans. 2013. V. 42. P. 10347. doi 10.1039/c3dt51098k

[13] Nikolaeva M.V., Katlenok E.A., Khakhalina M.S., Puzyk M.V., Balashev K.P. // J. Phys: Conference Series. 2014. V. 541. N 12014. P. 012086. doi 10.1088/1742-6596/541/1/012086

[14] Nikolaeva M.V., Katlenok E.A., Khakhalina M.S., Puzyk M.V., Balashev K.P. // J. Phys: Conference Series. 2015. V. 643. N 12. P. 012045. doi 10.1088/1742-6596/643/1/012045

[15] Eremina A.A., Kinzhalov M.A., Katlenok E.A., Smirnov A.S., Andrusenko E.V., Pidko E.A., Suslonov V.V., Luzyanin K.V. // Inorg. Chem. 2020. V. 59. N 4. P. 2209. doi 10.1021/acs.inorgchem.9b02833

[16] Gasser G., Ott I., Metzler-Nolte N. // J. Med. Chem. 2011. V. 54. N 1. P. 3. doi org/10.1021/jm100020w

[17] Гордон А., Форд Р. Спутник химика. М.: Мир, 1976; Gordon A.J., Ford R.A. The Chemist's Companion: A Handbook of Practical Data, Techniques, and References. 1st Edition. 1976.

[18] Накамото К. ИК спектры и спектры КР неорганических и координационных соединений. М.: Мир, 1992. 300 с.

[19] Сахаров С.Г., Ковалев В.В., Горбунова Ю.Е., Токмаков Г.П., Скабицкий И.В., Кокунов Ю.В. // Коорд. химия. 2017. T. 43. № 2. C. 67. Sakharov S.G., Kovalev V.V., Gorbunova Yu.E., Tokmakov G.P., Skabitskii I.V., Kokunov Yu.V. // Russ. J. Coord. Chem. 2017. V. 43. N 2. P. 75. doi 10.1134/S1070328417010079

[20] Dokalik A., Kalchhauser H., Mikenda W., Schweng G. // Magn. Reson. Chem. 1999. V. 37. N 12. P. 895. doi 10.1002/(SICI)1097-458X(199912)37:12<895::AIDMRC581>3.0.CO;2-7

[21] Marciniec K., Maślankiewicz A., Maślankiewicz M.J., Kurczab R. // J. Mol. Struct. 2012. V. 1015. P. 46. doi 10.1016/j.molstruc.2012.01.049

[22] Котлова И.А., Колоколов Ф.А., Доченко В.В., Аксенов Н.А., Аксенова И.В. // ЖОХ. 2019. Т. 89. В. 12. С. 1901. Kotlova I.A., Kolokolov F.A., Dotsenko V.V., Aksenov N.A., Aksenova I.V. // Russ. J. Gen. Chem. 2019. V. 89. N 12. P. 2413. doi 10.1134/S1070363219120144

[23] Mamedov V.A., Mamedova V.L., Khikmatova G.Z., Mahrous E.M., Korshin D.E., Syakaev V.V., Fayzullin R.R., Mironova E.V., Latypov Sh.K., Sinyashin O.G. // Russ. Chem. Bull., Int. Ed. 2019. V. 68. N 5. P. 1020. doi 10.1007/s11172019-2513-4

[24] Shanahan R.M., Hickey A., Bateman L.M., Light M.E., McGlacken G.P. // J. Org. Chem. 2020. V. 85. N 4. P. 2585. doi 10.1021/acs.joc.9b03321

[25] Carlton L., Belciug M.-P. // J. of Organomet. Chem. 1989. V. 378. N 3. P. 469. doi 10.1016/0022-328X(89)85371-9

[26] De Armond M., Carlin C. // Coord. Chem. Rev. 1985. V. 36. P. 325. doi 10.1016/S0010-8545(00)80502-0

[27] Katlenok E.A., Balashev K.P. // Russ. J. Gen. Chem. 2017. V. 87. N 2. P. 293. doi 10.1134/S1070363217020232

[28] Katlenok E.A., Balashev K.P. // Opt. Spectrosc. 2013. V. 115. N 4. P. 518. doi 10.7868/S0030403413040107

[29] Ghedini M., Aiello I., Crispini A., Golemme A., La Deda M., Pucci D. // Coord. Chem. Rev. 2006. V. 250. P. 1373. doi 10.1016/j.ccr.2005.12.011 